\title{
Insights into Corrosion Inhibition Behavior of a 5-Mercapto-1, 2, 4-triazole Derivative for Mild Steel in Hydrochloric Acid Solution: Experimental and DFT Studies
}

\author{
Israa Abd Alkadir Aziz ${ }^{1}$, Iman Adnan Annon ${ }^{1}$, Makarim H. Abdulkareem ${ }^{1}$, Mahdi M. Hanoon ${ }^{1}$, \\ Mohammed H. Alkaabi ${ }^{2}$, Lina M. Shaker ${ }^{3,4}$, Ahmed A. Alamiery ${ }^{4,5, *}$, Wan Nor Roslam Wan Isahak ${ }^{4}$ (D) \\ and Mohd S. Takriff 4,6
}

check for updates

Citation: Alkadir Aziz, I.A.; Annon, I.A.; Abdulkareem, M.H.; Hanoon, M.M.; Alkaabi, M.H.; Shaker, L.M.; Alamiery, A.A.; Wan Isahak, W.N.R.; Takriff, M.S. Insights into Corrosion Inhibition Behavior of a 5-Mercapto-1 2, 4-triazole Derivative for Mild Steel in Hydrochloric Acid Solution: Experimental and DFT Studies. Lubricants 2021, 9, 122. https:// doi.org/10.3390/lubricants9120122

Received: 28 October 2021

Accepted: 2 December 2021

Published: 10 December 2021

Publisher's Note: MDPI stays neutral with regard to jurisdictional claims in published maps and institutional affiliations.

Copyright: (c) 2021 by the authors. Licensee MDPI, Basel, Switzerland. This article is an open access article distributed under the terms and conditions of the Creative Commons Attribution (CC BY) license (https:// creativecommons.org/licenses/by/ $4.0 /)$.
1 Production Engineering and Metallurgy, University of technology, Baghdad 10001, Iraq; Iraa.a.aziz@uotechnology.edu.iq (I.A.A.A.); 70039@uotechnology.edu.iq (I.A.A.); 70008@uotechnology.edu.iq (M.H.A.); 70182@uotechnology.edu.iq (M.M.H.)

2 College of Industrial Management of Oil and Gas, Basrah University of oil and Gas, Basrah 61001, Iraq; mohammedhalkaabi@gmail.com

3 Medical Instruments Technology Engineering, Al Mansour University College, Baghdad 10001, Iraq; linamohmmed91@gmail.com

4 Department of Chemical and Process Engineering, Faculty of Engineering and Built Environment, Universiti Kebangsaan Malaysia (UKM), Bangi 43600, Selangor, Malaysia; wannorroslam@ukm.edu.my (W.N.R.W.I.); sobritakriff@ukm.edu.my (M.S.T.)

5 Energy and Renewable Energies Technology Center, University of Technology, Baghdad 10001, Iraq

6 Chemical and Water Desalination Engineering Program, Department of Mechanical \&Nuclear Engineering, Collage of Engineering, University of Sharjah, Sharjah, United Arab Emirates

* Correspondence: dr.ahmed1975@ukm.edu.my

Abstract: A triazole heterocyclic compound namely 3-(4-ethyl-5-mercapto-1, 2, 4-triazol-3-yl)-1phenylpropanone (EMTP) was examined for its corrosion protection of mild steel (MS) against $1 \mathrm{M}$ hydrochloric acid medium using gravimetric techniques. EMTP exhibited excellent corrosion protection performance at low and high concentrations towards MS in $\mathrm{HCl}$ solution. Comparison of corrosion protection performance of EMTP and its parent triazole and temperature effects of on inhibition efficacy were also studied. EMTP has potential corrosion inhibitor for mild steel in $1.0 \mathrm{M}$ hydrochloric acid solution with the highest protection efficacy of $97 \%$ at $303 \mathrm{~K}$. The weight loss findings implied that EMTP protects the metal surface corrosion through the creation of a protective layer at the surface mild steel-corrosive solution interface. The inhibitive efficacy increases with the increase of inhibitor concentration and decreases with increased temperature. The adsorption of EMTP on the surface of MS follows Langmuir's adsorption isotherm process. DFT method was conducted on EMTP molecule to calculate the quantum chemical parameters and to determine the relationship between the molecular structure of EMTP and protection performance. The molecular parameters, such as energy gap and frontier molecular orbital (highest occupied molecular orbital (HOMO) and lowest unoccupied molecular orbital (LUMO)), and the absolute electronegativity $(\chi)$ value from inhibitor molecules to unoccupied d-orbital of iron atoms on the mild steel surface were also determined and correlated with protection efficiency. The theoretical findings revealed that the protection performance of EMTP increased with the increase in HOMO energy, and the nitrogen, oxygen and sulfur atoms are most probable positions for bonding through giving electrons to the d-orbital of iron atoms on the mild steel surface.

Keywords: corrosion inhibition; phenylpropanone; EMTP; weight loss; DFT

\section{Introduction}

The widespread use of hydrochloric acid for pickling, rescaling, and cleaning mild steel (MS) surfaces causes' severe corrosion concerns. Inhibitors can prevent the corrosion 
of metallic materials by limiting metal solubility and consumption. Organic molecules containing nitrogen, oxygen, and/or sulfur atoms, as well as N-heterocyclic compounds with polar groups and/or p-electrons, are the most common acid inhibitors [1]. Several five-membered heterocycles were examined in the recent decade, and analysis has shown that the large percentage of triazoles have good corrosion protection performance for shielding a variety of alloys and metals (particularly mild steel) [2,3]. Various triazoles have been tried as corrosion inhibitors, with the results indicating that transferring a triazole to its derivatives improves inhibition performance [4-7]. Zhang et al. investigated the corrosion protection of a novel synthesized triazole derivative for mild steel in $\mathrm{H}_{2} \mathrm{SO}_{4}$ environment, and their findings showed that the novel compound was an effective mild steel corrosion inhibitor in acid solution, with an efficiency of more than $97.6 \%$ at $298 \mathrm{~K}$ [8]. Wang et al. also studied the corrosion of mild steel in $\mathrm{HCl}$ medium using thiol-triazoles with various hetero atoms and substituents in the organic structures, and their findings revealed that all the thiol-triazole derivatives performed exceptionally well as corrosion inhibitors [9]. Some nitrogen, oxygen, and sulfur-containing triazole compounds, in particular, are more eco-friendly corrosion inhibitors than some commercial corrosion inhibitors, such as nitrite or chromate, which are severely polluting [10]. The adsorption of organic corrosion inhibitors on the metal-solution interface is usually the essential step in the effectiveness of organic corrosion inhibitors in acidic environments [11]. Corrosion inhibitors may be classified as cathodic, anodic, or mixed, depending on whether their influence is mainly in retarding the cathodic or anodic reaction of the corrosion process or both. The inhibition of anodic or cathodic corrosion reactions can be due to the reduction of the active surface area of metal and/or to a change of the activation energy of the oxidation or reduction process in corrosion. The combination of cathodic and anodic corrosion inhibitors often determines improved protection and allows reduction of the inhibitor concentration. There are usually three types of adsorption processes, physical adsorption (physisorption), chemical adsorption (chemisorption), or a combination of both-depending on the nature of the forces involved in limiting the process. A mixed-type inhibitor is a formal name for this sort of corrosion inhibitor. Adsorption requires the presence of attractive forces between the adsorbate and the mild steel. Electric charges at the surface of mild steel and charged species in the solution bulk are required for physical adsorption. The potential of the electric charges on the mild steel surface can be measured in comparison to zero charge potential. The presence of unpaired electrons, or a pi-electron system conjugated with benzene rings or triple bonds, favors electron transfer from the inhibitor molecules to the unoccupied d-orbital in the iron atoms located on the surface of mild steel. It can happen when there are heteroatoms $(\mathrm{N}, \mathrm{O}, \mathrm{S}$, and $\mathrm{P})$ in the adsorbed materials, as well as lone-pair and/or aromatic units. In general, as the electrons become more loosely held, i.e., decreasing electronegativity in the order $\mathrm{O}<\mathrm{N}<\mathrm{S}<\mathrm{P}$, the tendency of elements to form stronger coordinated bonds increases [12-21]. This compound was prepared previously [22] and as indicated in the preparation method, but it was not previously used as an anticorrosion, so its use as an anticorrosion is considered for the first time. As a result, for the first time, we describe the assessment of EMTP as a mild steel corrosion inhibitor (Figure 1) in $1 \mathrm{M} \mathrm{HCl}$ using weight loss techniques in this study. The immersion time was also studied. The inhibitory process was also subjected to an appropriate adsorption isotherm.

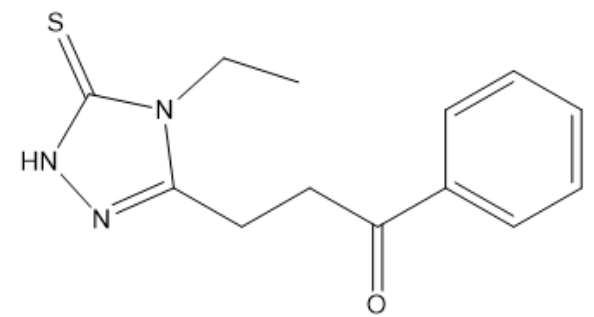

Figure 1. Structure of 3-(4-ethyl-5-mercapto-1,2,4-triazol-3-yl)-1-phenylpropanone (EMTP). 


\section{Materials and Methods}

\subsection{Materials}

The inhibitory effects of EMTP are examined on mild steel with the chemical composition presented in Table 1.

Table 1. Chemical composition of the mild steel coupon (wt.\%).

\begin{tabular}{ccccccc}
\hline Carbon & Manganese & Silicon & Aluminum & Sulfur & Phosphorus & Iron \\
\hline 0.210 & 0.050 & 0.380 & 0.010 & 0.050 & 0.090 & balance \\
\hline
\end{tabular}

\subsection{Inhibitor}

The triazole EMTP was synthesized by refluxing an aqueous sodium hydroxide (100 mL, 2 M) and 4-ethyl-1-(4-keto-4-phenylbutanoyl)thiosemicarbazide (1.82 g, 0.02 mol) in a reflux condenser for $8 \mathrm{~h}$. The solution was further concentrated, cooled, and neutralized with $\mathrm{HCl}$ and the compound formed was separated by filtration, recrystallized from xylene and characterized using Fourier Transform Infrared (FTIR), Nuclear Magnetic Resonance (NMR) and micro-elemental analysis (CHN) as reported previously [22]. Yield, $73 \% . \mathrm{MP}=210{ }^{\circ} \mathrm{C}$. CHN analysis for the EMTP with the chemical formula $\mathrm{C}_{13} \mathrm{H}_{15} \mathrm{~N}_{3} \mathrm{OS}$, calculated (found): C, 59.74 (58.82,), H, 5.79 (4.83), N, 16.08 (15.21). Fourier Transform Infrared (FTIR) Spectroscopy is used to determines the chemical structure of organic compounds. The FTIR peak at $3299 \mathrm{~cm}^{-1}$ represents the bond between nitrogen and hydrogen in amino group $(\mathrm{N}-\mathrm{H}), 3061 \mathrm{~cm}^{-1}$ refers to carbon-hydrogen bond in the aromatic ring (C-H aromatic), $2935 \mathrm{~cm}^{-1}$ signifies to carbon-hydrogen bond in the aliphatic group (CH aliphatic), $1727 \mathrm{~cm}^{-1}$ represents the carbon-oxygen bond in the carbonyl group $(\mathrm{C}=\mathrm{O}$ benzoyl), $1630 \mathrm{~cm}^{-1}$ is the bond in azomethine group between the carbon-nitrogen $(\mathrm{C}=\mathrm{N})$, $1603 \mathrm{~cm}^{-1}$ for double bond between carbon-carbon in aromatic ring $(C=C)$, and finally the peak at $1348 \mathrm{~cm}^{-1}$ represents the bond between arbon-sulfur $(\mathrm{C}=\mathrm{S}) .{ }^{1} \mathrm{H}-\mathrm{NMR}\left(\mathrm{DMSO}-\mathrm{d}^{6}\right)$ : $1.34\left(3 \mathrm{H}, \mathrm{t}, \mathrm{CH}_{3}\right), 2.98\left(2 \mathrm{H}, \mathrm{t}, \mathrm{CH}_{2}-\mathrm{CH}_{3}\right), 3.23\left(2 \mathrm{H}, \mathrm{t}, \mathrm{CH}_{2}-\mathrm{CH}_{2}\right), 4.27\left(2 \mathrm{H}, \mathrm{q}, \mathrm{CH}_{2} \mathrm{CO}\right)$, 7.44-7.922 (3H, dd, aromatic), $7.61\left(1 \mathrm{H}, \mathrm{t}\right.$, aromatic), $7.79\left(2 \mathrm{H}, \mathrm{dd}, \mathrm{CH}_{2} \mathrm{CO}\right), 11.97(1 \mathrm{H}, \mathrm{s}$, amine). The chemical structure of the synthesized triazole EMTP is presented in Figure 1.

\subsection{Corrosive Media}

The corrosive solution was prepared by diluting 37\% $\mathrm{HCl}$ (Merck-Malaysia) using distilled water.

\subsection{Weight Loss}

To study the inhibition properties of proposed compound, various concentrations of the inhibitor $(100,200,300,400,500$, and 1000 ppm) were added to the hydrochloric acid medium at a constant temperature $303 \mathrm{~K}$. The blank test solution was $150 \mathrm{~mL}$ of $1 \mathrm{M} \mathrm{HCl}$ without inhibitor. Before each experiment, the mild steel coupons were mechanically well polished with various grades SiC (200-600) emery papers and rinsed with methyl alcohol, dimethyl ketone, and distilled water before being dried and weighed. Weight loss analyses were conducted by measuring dried mild steel coupons before and after immersion in $1 \mathrm{M} \mathrm{HCl}$ environments from 1 to $48 \mathrm{~h}$ in the absence and presence of a different concentrations of inhibitor at $303 \mathrm{~K}$. Experiments were repeated for three times to determine average values. Rate of corrosion $\left(C_{R}\right)$ has been determined from the mass loss techniques according to ASTM G-31-72 method and the protection efficacy (IE\%) was evaluated also. The corrosion rate and inhibition efficiency values were calculated according to Equations (1) and (2). Mass loss analysis has been conducted at temperatures ranging $303,313,323$, and $333 \mathrm{~K}$ without and with various concentrations of tested inhibitor. The temperatures were selected based on previous studies [23-26].

$$
C_{R}=\frac{87600 W}{a t d}
$$


where $W$ is the mild steel sample mass loss in " $\mathrm{g}$ ", $a$ is the mild steel sample surface area in $\mathrm{cm}^{2}, t$ is the exposure time in $\mathrm{h}$, and $d$ is the mild steel sample density in $\mathrm{g} / \mathrm{cm}^{3}$.

$$
I E \%=\left[\frac{C_{R(\mathrm{o})}-C_{R(\mathrm{i})}}{C_{R(\mathrm{o})}} \times 100\right]
$$

where $C_{R(\mathrm{o})}$ is the rate of corrosion in the absence of inhibitor, and $C_{R(\mathrm{i})}$ is the rate of corrosion in the presence of inhibitor.

\subsection{Computational Details}

Quantum chemical calculations have been conducted for gas phases applying density functional theory (DFT) techniques, using the conventional theory regarding Becke's threeparameter hybrid functional (B3LYP) level through Gaussian 03 series with 6-31G as basis set. All the calculations were calculated using of the ChemOffice program. Physical parameters such as the energy of highest occupied molecular orbital energy $\left(\mathrm{E}_{\mathrm{HOMO}}\right)$, energy of lowest unoccupied molecular orbital energy ( $\left.\mathrm{E}_{\mathrm{LUMO}}\right)$, energy gap $\Delta \mathrm{E}=\mathrm{E}_{\mathrm{HOMO}}-\mathrm{E}_{\mathrm{LUMO}}$, chemical hardness $(\eta)$, chemical softness $(\sigma)$, and electronegativity $(\chi)$, were calculated according to Equations (3)-(6) [27];

$$
\begin{gathered}
\Delta E=E_{\text {HOMO }}-E_{\text {LUMO }} \\
\eta=-\frac{E_{\text {HOMO }}-E_{\text {LUMO }}}{2} \\
\sigma=\frac{1}{\eta} \\
\chi=-\frac{E_{\text {HOMO }}+E_{\text {LUMO }}}{2}
\end{gathered}
$$

\section{Results and Discussion}

\subsection{Weight Loss Techniques}

The corrosion rate $\left(\mathrm{C}_{\mathrm{R}}\right)$ and corrosion protection efficiency (IE\%) collected from the mass loss techniques in the presence and absence of various concentrations of EMTP for mild steel in 1.0 M hydrochloric acid solution are shown in Figure 2. The corrosion protection performance was evaluated at $303 \mathrm{~K}$ and various immersion periods [28,29].

According to Figure 2, it is obvious that the mild steel corrosion rate reduced significantly, and the protection efficacy increased with the increase in EMTP concentration. The increased inhibiting efficacy can be attributed to the increased surface coverage owing to the adsorption of inhibitor molecules on the surface of mild steel [30,31]. The adsorption layer may then block the active sites, effectively isolating the tested coupon from the acidic environment. Compared with the triazoles corrosion inhibitors investigated previously (Table 2), EMTP showed more favorable corrosion-inhibiting performance [32,33]. 


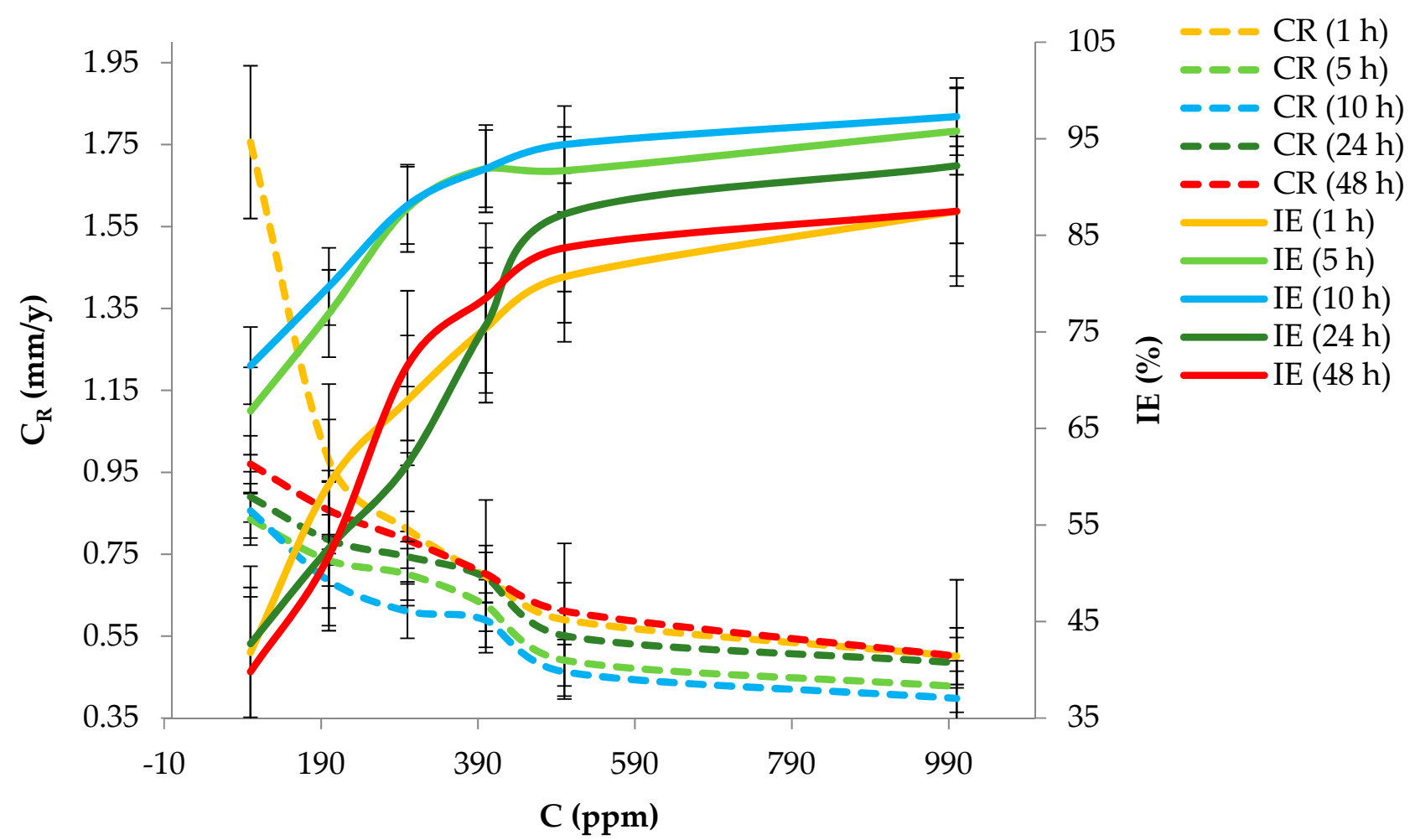

Figure 2. Results of mass loss techniques of mild steel in $1.0 \mathrm{M} \mathrm{HCl}$ with various concentrations of EMTP at $303 \mathrm{~K}$ and different immersion time.

Table 2. EMTP inhibitory efficiency was compared quantitatively to that of other triazoles recently examined.

\begin{tabular}{|c|c|c|}
\hline Inhibitor & IE\% & Ref. \\
\hline EMTP & 97 & Current inhibitor \\
\hline ethyl 2-(4-phenyl-1H-1,2,3-triazol-1-yl) acetate & 95.3 & [33] \\
\hline 2-(4-phenyl-1H-1,2,3-triazol-1-yl) acetohydrazide & 95 & [33] \\
\hline 7-((1-benzyl-1H-1,2,3-triazol-4-yl)methyl)-1,3-dimethyl-3,7-dihydro-1H-purine-2,6-dione & 91.7 & [34] \\
\hline 7-((1-(4-fluorobenzyl)-1H-1,2,3-triazol-4-yl)methyl)-1,3-dimethyl-3,7-dihydro-1H-purine-2,6-dione & 86.9 & [34] \\
\hline 7-((1-(4-chlorobenzyl)-1H-1,2,3-triazol-4-yl)methyl)-1,3-dimethyl-3,7-dihydro-1H-purine-2,6-dione & 94.0 & [34] \\
\hline 7-((1-(4-bromobenzyl)-1H-1,2,3-triazol-4-yl)methyl)-1,3-dimethyl-3,7-dihydro-1H-purine-2,6-dione & 91.8 & [34] \\
\hline 7-((1-(4-iodobenzyl)-1H-1,2,3-triazol-4-yl)methyl)-1,3-dimethyl-3,7-dihydro-1H-purine-2,6-dione & 90.9 & [34] \\
\hline 5-methyl-4-((3-nitrobenzylidene) amino) -2,4-dihydro-3H-1,2,4-triazole-3-thione & 89.74 & [35] \\
\hline 3-phenyl-4-amino-5-mercapto-1,2,4-triazole & 97 & [36] \\
\hline 2[5-(2-Pyridyl)-1,2,4-triazol-3-yl phenol & 96.8 & [37] \\
\hline 3,5-Bis(4-methyltiophenyl)-4H-1,2,4-triazole & 93.5 & [37] \\
\hline 3,5-Bis(4-pyridyl)-4H-1,2,4-triazole & 89.1 & {$[37]$} \\
\hline 3,5-Diphenyl-4H-1,2,4-triazole & 82.8 & [38] \\
\hline 3,5-Di(m-tolyl)-4-amino-1,2,4-triazole & 24 & [39] \\
\hline 5-Amino-1,2,4-triazole & 90 & [39] \\
\hline 5-Amino-3-mercapto-1,2,4-triazole & 82 & [39] \\
\hline 5-Amino-3-methyl thio-1,2,4-triazole & 82 & [39] \\
\hline 1-Amino-3-methyl thio-1,2,4-triazole & 63 & [40] \\
\hline 3-Benzylidene amino-1,2,4-triazole phosphonate & 56.9 & [40] \\
\hline 3- $p$-Nitro-benzylidene amino-1,2,4-triazole phosphonate & 69.23 & [40] \\
\hline 3-Salicylialidene amino-1,2,4-triazole phosphonate & 43.2 & {$[40]$} \\
\hline 3,5-Bis(methylene octadecyldimethylammonium chloride)-1,2,4-triazole & 98.3 & [41] \\
\hline 3-Amino-1,2,4-triazole-5-thiol & 97.8 & [42] \\
\hline
\end{tabular}

In $\mathrm{HCl}$ solutions, the inhibition efficacy of the current inhibitor (EMTP) can be compared with other reported inhibitors that use corrosion inhibitors derived from triazoles to protect the corrosion of mild steel. Table 2 shows that the majority of triazoles examined 
have strong inhibitory efficacy. To make the comparison with the current inhibitor in question, EMTP has the greatest inhibitory efficiency compared to triazoles mentioned in Table 2 [33-35,37-40], as well as an efficiency equivalent to that described in [36,41,42]. It is obvious that when the concentration of EMTP increased, the rate of corrosion reduced, and the inhibitive efficacy improved. This could be caused by the inhibitor's adsorption coverage on mild steel surfaces increases as the EMTP concentration increased.

The increase in protection efficacy is attributed to the increase in surface coverage because of the adsorption of the inhibitor molecules on the surface of mild steel. Next, the adsorption layer blocks the active sites and isolates the mild steel surface from the acidic environment. Related to the initial investigated triazoles inhibitors in Table 2, EMTP showed excellent corrosion protection performance. This phenomenon is related to the effects of steric hindrance and the heteroatoms in the inhibitor molecular structure. When the inhibitor is added to the corroding solution with a concentration of $500 \mathrm{ppm}$, the highest inhibitory efficacy was obtained. The increase in concentration (to $1000 \mathrm{ppm}$ ) did not lead to a significant change in the inhibitory efficiency.

\subsection{Effect of Immersion Time}

Weight loss findings showed that the inhibition efficiency increased as the concentration and immersion time increased. The highest inhibitive efficacy of about $97 \%$ was achieved at $500 \mathrm{ppm}$ concentration after $5 \mathrm{~h}$ immersion. There is no significant increase in the inhibitive efficacy after $5 \mathrm{~h}$ of exposure time, and decline of inhibition efficiency after $24 \mathrm{~h}$, this is attributed to desorption of the tested inhibitor molecules from the mild steel surface with increasing exposure time and instability of the protective layer on the mild steel surface [43]. A remarkable decline in the inhibition efficiency has appeared after immersion for $48 \mathrm{~h}$.

\subsection{Effect of Temperature}

The temperature effects on corrosion rate and inhibition efficiency were investigated in $1 \mathrm{M} \mathrm{HCl}$ in the temperature range of 303-333 $\mathrm{K}$ without and with various inhibitor concentrations as shown in Figure 3. The optimum immersion time (10 h) was selected based on the highest inhibition efficacy obtained from comparing all tested concentrations. A decrease in the protection efficiency was observed with rising temperature from 303 to $333 \mathrm{~K}$. The desorption of adsorbed inhibitor molecules on the mild steel surface could explain this phenomenon. Thus, the inhibition occurs because of the inhibitor adsorption on the mild steel surface, and increasing temperature will facilitate the desorption process of inhibitor molecules from mild steel surface [44].

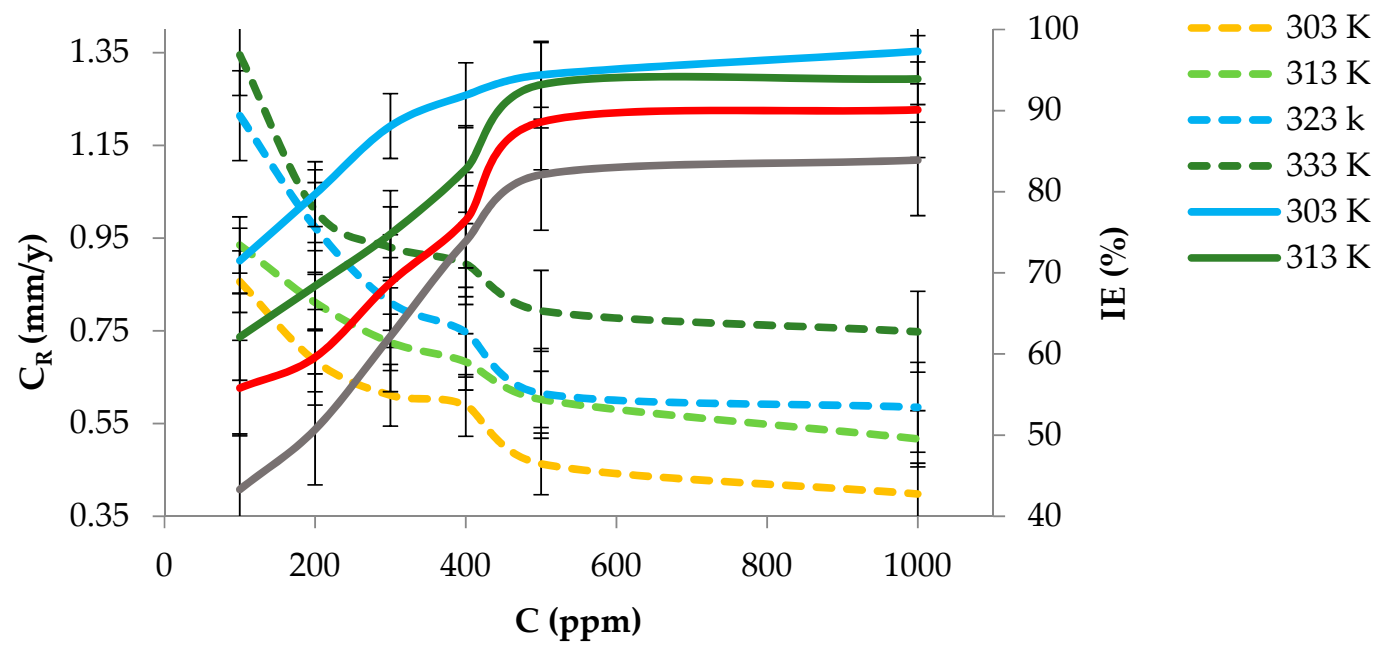

Figure 3. Results of mass loss techniques of mild steel in $1.0 \mathrm{M} \mathrm{HCl}$ with various concentrations of EMTP at $333 \mathrm{~K}$ and different immersion time. 
The activation parameters of corrosion process have been evaluated based on Arrhenius Equation (7):

$$
\log C_{R}=\log k-\left\{\frac{E_{a}}{2.303 R T}\right\}
$$

where $E_{a}$ represents the activation energy, $k$ is the frequency parameter, $T$ is the temperature and $R$ is the gas constant.

The activation energy value for mild steel in $1 \mathrm{M} \mathrm{HCl}$ in absence and presence of different inhibitor concentrations were determined from Figure 4 between $\log C_{R}$ and $1 / T$ [45]. Figure 4 gives a straight line with slope of $-E_{a} / 2.303 R$ from which the $E_{a}$ was calculated and presented in Table 3. With increasing temperature, there is an appreciable decrease in the adsorption of the inhibitors on the metal surface, and a corresponding rise in the corrosion rate occurred. As the temperature rises, the adsorption of inhibitor molecules on the mild steel surface decreases, and the rate of corrosion rises in response.

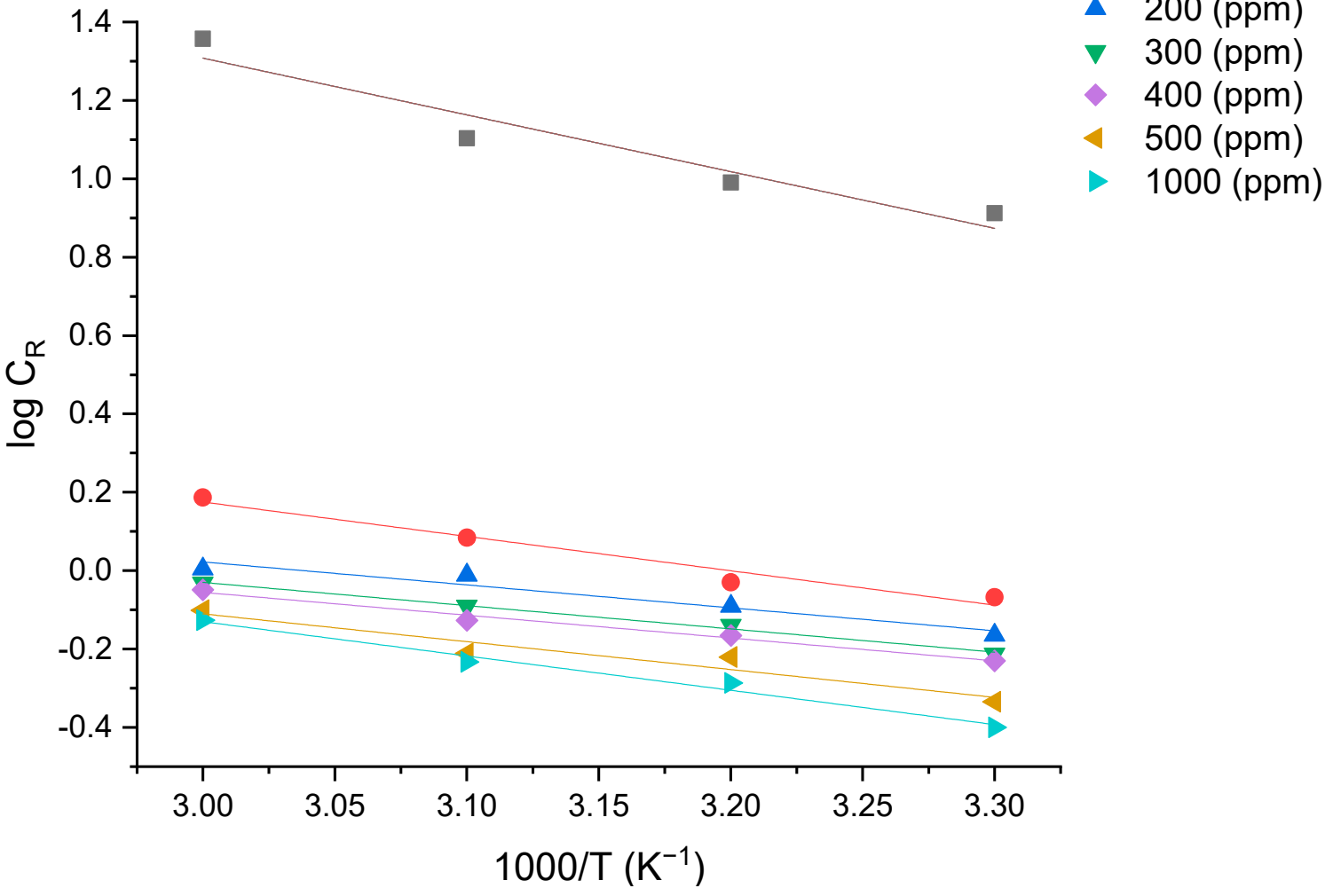

$0.00(\mathrm{ppm})$

- 100 (ppm)

- 200 (ppm)

$\checkmark 300$ (ppm)

400 (ppm)

$500(\mathrm{ppm})$

1000 (ppm)

Figure 4. The $\log C_{R}$ vs. $1 / T$ for the various concentrations of EMTP and different Temperature.

Table 3. The activation parameters values for mild steel in $1 \mathrm{M} \mathrm{HCl}$ solution in the absence and presence of different concentrations of EMTP.

\begin{tabular}{|c|c|c|c|}
\hline$C($ ppm) & $E_{a}\left(\mathrm{~kJ} \mathrm{~mol}^{-1}\right)$ & $\Delta H_{a}\left(\mathrm{~kJ} \mathrm{~mol}^{-1}\right)$ & $\Delta S_{a}\left(\mathrm{~J} \mathrm{~mol}^{-1} \mathbf{K}^{-1}\right)$ \\
\hline 0.00 & 62.96 & 59.83 & 56.87 \\
\hline 100 & 45.65 & 43.18 & 123.68 \\
\hline 200 & 43.23 & 41.38 & 117.67 \\
\hline 300 & 44.74 & 41.95 & 113.88 \\
\hline 400 & 46.73 & 42.54 & 112.84 \\
\hline 500 & 48.05 & 44.75 & 111.85 \\
\hline 1000 & 48.91 & 44.53 & 110.17 \\
\hline
\end{tabular}


$E_{a}$ values for inhibited systems are higher than those for the uninhibited systems indicates that dissolution of mild steel is slow. Moreover, as the inhibitor concentration increases the values of $E_{a}$ also increases. This suggests the presence of the inhibitor induces an energy barrier for corrosion reaction and the barrier increases with increasing concentration. At higher temperatures, there is an appreciable decrease in the adsorption of the inhibitors on the metal surface and a corresponding rise in the corrosion rate occurred.

A modified Arrhenius plot of $\log C_{R} / T$ versus $1 / T$ for mild steel dissolution in $1 \mathrm{M} \mathrm{HCl}$ environment allows for determining the values of the enthalpy of activation $\left(\Delta H_{a}\right)$ and the entropy of activation $\left(\Delta S_{a}\right)$ based on Equation (8):

$$
\log \left\{\frac{C_{R}}{T}\right\}=\left[\left\{\log \left\{\frac{R}{N h}\right\}+\left\{\frac{\Delta S_{a}}{2.303 R}\right\}\right\}\right]-\left(\frac{\Delta H_{a}}{2.303 R T}\right)
$$

where $N$ represents Avogadro's number, $h$ refers to Plank's constant.

A plot of $\log \left(C_{R} / T\right)$ versus $1 / T$ is shown in Figure 5. The values of enthalpy of activation $\left(\Delta H_{a}\right)$ and the entropy of activation $\left(\Delta S_{a}\right)$ were obtained from the slope and intercept of Figure 5 and demonstrated in Table 3. The endothermic character of mild steel dissolution is reflected by the positive values of $\Delta H_{a}\left(59-44 \mathrm{~kJ} \mathrm{~mol}^{-1}\right)$. The reduction in mild steel $C_{R}$ is essentially regulated by the kinetic parameters of activation, as observed by the improvement in $\mathrm{H}$ with rising inhibitor concentration.

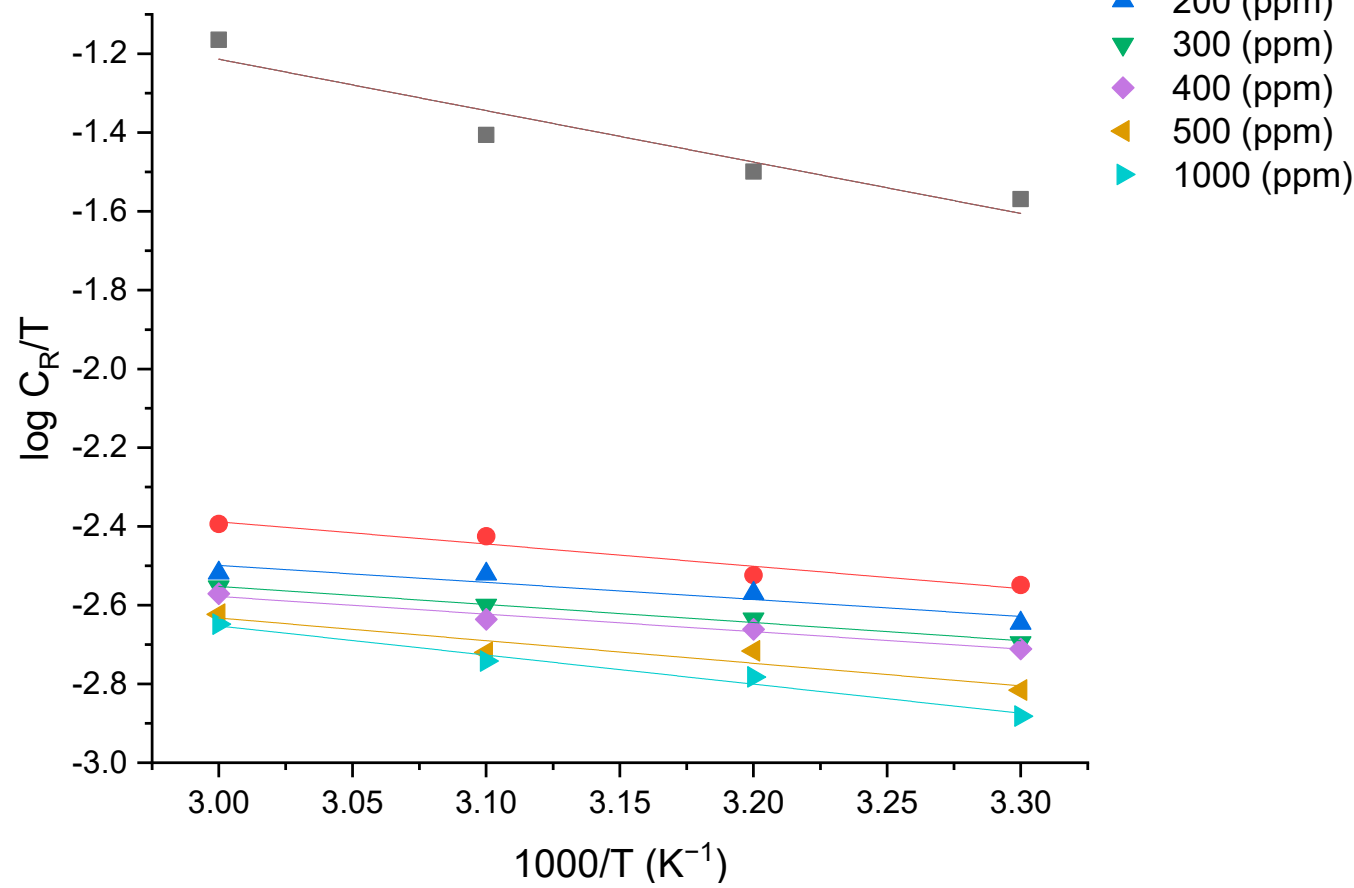

Figure 5. A modified Arrhenius plot of $\log C_{R} / T$ versus $1 / T$ for mild steel in the absence and presence of tested inhibitor.

The enthalpy of activation values in absence $(0.0 \mathrm{ppm})$ and in the presence of tested inhibitor (500 ppm) were $59.83 \mathrm{~kJ} \mathrm{~mol}^{-1}$ and $44.75 \mathrm{~kJ} \mathrm{~mol}^{-1}$ respectively (Table 3 ) and were obtained from the slope of Figure 5, whereas the entropy of activation values in absence and in the presence of tested inhibitor were $56.87 \mathrm{~J} \mathrm{~mol}^{-1}$ and $110.17 \mathrm{~J} \mathrm{~mol}^{-1}$ respectively and were determined from the intercept of Figure 5. Positive $\Delta H_{a}$ values without and with the addition of tested inhibitor suggests that the mild steel dissolving process is endothermic $[46,47]$. 


\subsection{Adsorption Isotherm}

In general, the protection performance of an EMTP molecule depends on the abilities of these molecules to be adsorbed on the mild steel surface. Hence, it is important to understand the adsorption isotherm which provides important knowledge about the inhibitor molecules interactions of inhibitor with the metal surface. The corrosion-inhibiting process of mild steel surface depends on how the inhibitor molecules are adsorbed on the metal surface (physisorption or chemisorption), as well as the nature and the molecular structure of the inhibitor molecules [48]. The inhibitor concentration and the surface coverage $(\theta)$ were investigated by plotting them with different adsorption models to find the most suitable adsorption isotherm. The equilibrium adsorption of the tested inhibitor follows the Langmuir adsorption model on metal in $1 \mathrm{M} \mathrm{HCl}$ solution. Based on this Langmuir model, surface coverage is linked to the inhibitor concentration and equilibrium constant $\left(K_{a d s}\right)$ according to Equation (9)

$$
\frac{C}{\theta}=\frac{1}{K_{a d s}}+C
$$

A straight line was obtained from plotting of $C / \theta$ vs $C$ as in Figure 6, and the value of linear correlation coefficient $\left(R^{2}\right)$ was found to be close to unity, which indicates that the adsorption mechanism of tested inhibitor molecules in acidic solution on mild steel surface follows Langmuir adsorption model. The $\Delta G_{a d s}^{o}$ value was determined according to Equation (10) [49]:

$$
\Delta G_{a d s}^{o}=-2.303 R T \log 55.5 K_{a d s}
$$

where $R$ represents the gas constant, $T$ is the temperature and the value 55.5 is the water molar concentration $\left(\mathrm{mol} \cdot \mathrm{L}^{-1}\right)$.

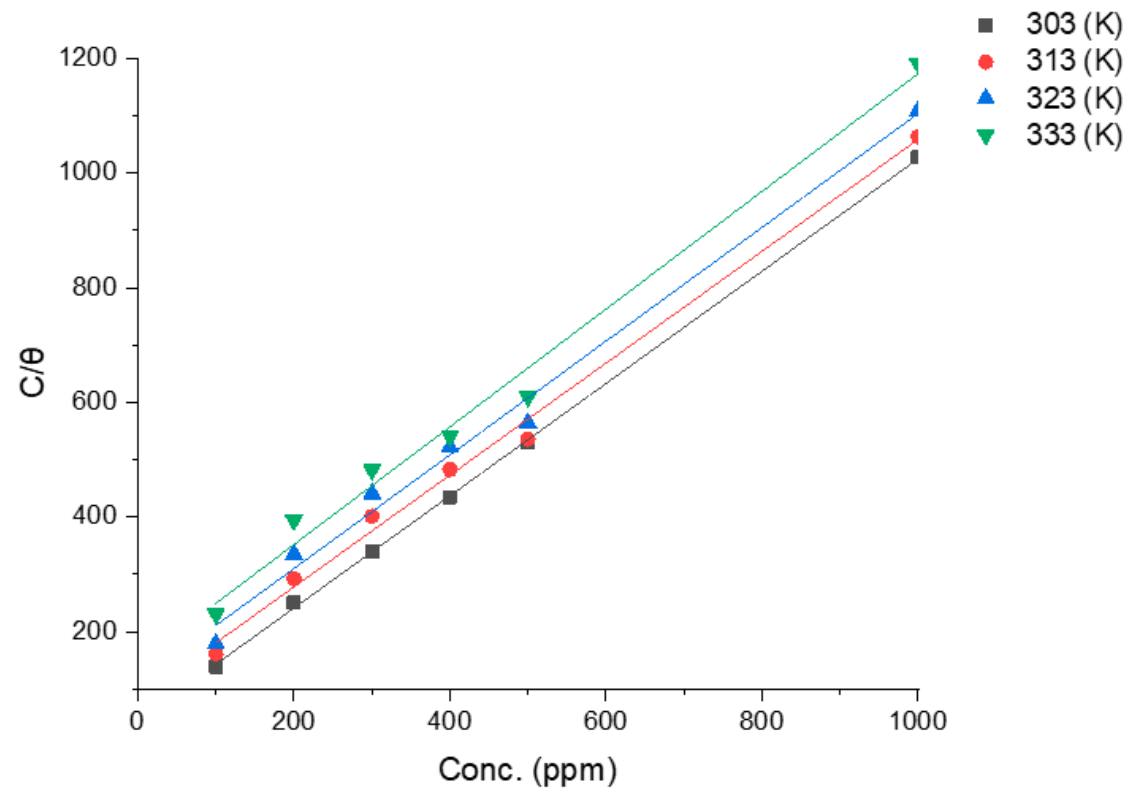

Figure 6. Langmuir's model plot for the adsorption of EMTP in $1 \mathrm{M} \mathrm{HCl}$ on mild steel at the temperature range 303 to $333 \mathrm{~K}$.

Previous studies confirmed that if the value of $\Delta G_{a d s}^{o}$ is negative, this indicates that the adsorption of the inhibitor molecules on the metal surface is spontaneous process [25]. In the current investigation, the value $\Delta G_{\text {ads }}^{o}$ for tested inhibitor is $-35.73 \mathrm{~kJ} \mathrm{~mol}^{-1}$ suggesting that the mechanism of adsorption obeys both physical (physisorption) and chemical (chemisorption) adsorption [50,51]. 


\subsection{Quantum Chemical Studies}

Quantum chemical calculations were conducted using the density functional theory with B3LYP at the basis set $6-31 G^{*}$. The quantum parameters were postulated in Table 4 . The energies of frontier MOs such as $E_{H O M O}$ and $E_{L U M O}$ are important factors to predict reactive chemical species. $E_{\text {HOMO }}$ (as in Figure 7) is usually associated with the molecule's ability to donate an electron. Hence, if an increase in the value of EHOMO indicates a greater tendency to donate electrons to the appropriate acceptor which has an unoccupied orbital. The high value of $E_{H O M O}$ facilitates the absorption of protective particles on the metal surface. The protective performance of the inhibitor increased by increasing the process of transport by the adsorbent film [52-54]. $E_{H O M O}$ with the negative value evaluated and other thermodynamic characteristics indicate that the obtained quantum chemical data confirms both physisorption and chemisorption mechanisms [55,56]. Previous studies exhibit that the $\Delta E$ with a high value indicates that the inhibitor molecules have low reactivity because the energy gap is related to the softness and/or hardness of the inhibitor molecules [57-60]. A hard molecule is less reactive than a soft one because the soft one has less energy gap. This shows that the $\Delta \mathrm{E}$ value, in addition to the value of dipole moment $(\mu)$ indicating the significant inhibition efficiency of the tested inhibitor molecules as protection corrosion for mild steel in $1 \mathrm{M} \mathrm{HCl}$ solution. There is an agreement by many researchers that the heteroatoms with high negative charge can be adsorbed on the mild steel surface by the mechanism of donors-acceptors reactions [61-63]. Furthermore, a less value of $\Delta E$, a high molecular weight, and a low value of electronegativity improve efficient adsorption of tested inhibitor molecules on the MS surface hence reducing the rate of corrosion of the MS surface.

Table 4. Quantum parameters for tested inhibitor molecule.

\begin{tabular}{cc}
\hline Quantum Characteristics & EMTP \\
\hline$E_{\text {HOMO }}(e V)$ & -8.251 \\
$E_{\mathrm{LUMO}}(\mathrm{eV})$ & -5.186 \\
$\Delta E=E_{H O M O}-E_{L U M O}(\mathrm{eV})$ & 3.065 \\
Dipole moment $(\mu)(\mathrm{D})$ & 2.800 \\
Global hardness $(\eta)$ & 1.530 \\
Global softness $(\sigma)$ & 0.660 \\
Electronegativity $(\chi)$ & 6.500 \\
\hline
\end{tabular}

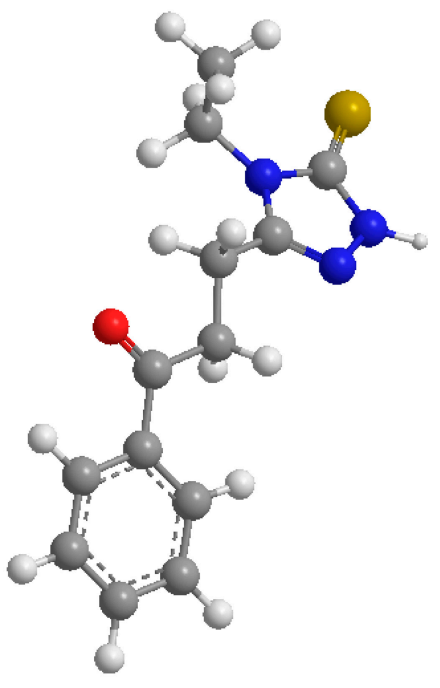

(a)
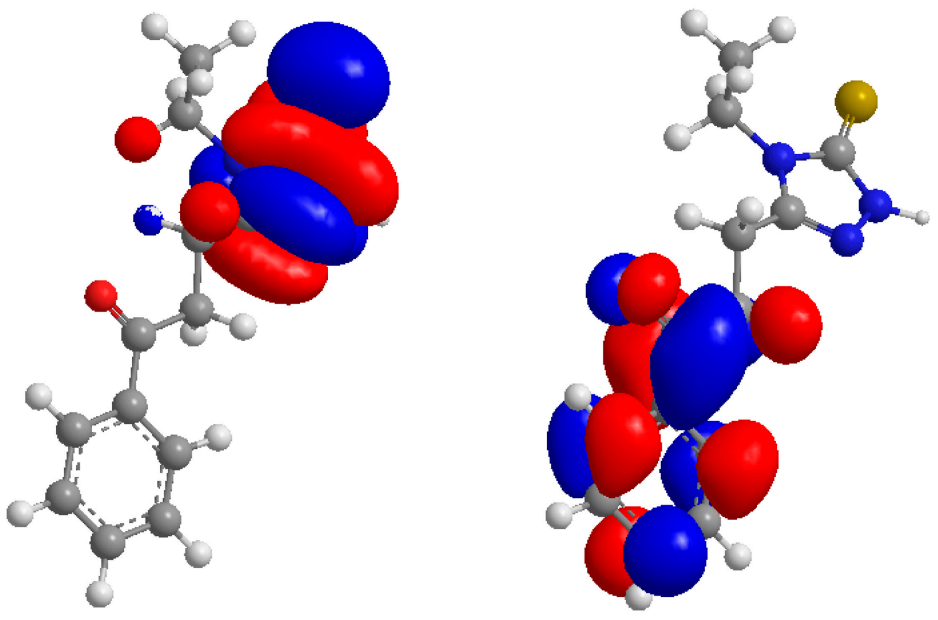

(b)

(c)

Figure 7. Optimized geometrical structure (a), $E_{H O M O},(\mathbf{b})$ and $E_{L U M O}(\mathbf{c})$ of EMTP. 


\subsection{Inhibition Mechanism}

The chemisorption processes can be used to define the adsorption of EMTP molecules on MS surfaces. The following relations (Equations (11)-(13)) describe the specific mechanism of EMTP molecules inhibition on the surface of mild steel coupons.

$$
\begin{gathered}
\mathrm{Fe}+\mathrm{EMTP} \leftrightarrow \mathrm{Fe}(\text { EMTP })_{a d s} \\
\mathrm{Fe}(\mathrm{EMTP})_{a d s} \leftrightarrow \mathrm{Fe}^{++}+\mathrm{EMTP}+n e^{-} \\
(\text {EMTP })_{a q}+\mathrm{H}_{2} \mathrm{O}_{a d s} \leftrightarrow(\text { EMTP })_{a d s}+\mathrm{H}_{2} \mathrm{O}_{a q}
\end{gathered}
$$

The chemical adsorption of EMTP molecules on MS surface is indicated through the interactions of donor/acceptor from the unreacted pairs of electrons of nitrogen, sulfur, and oxygen atoms of tested inhibitor molecules with the unoccupied d-orbital of iron atoms on the mild steel surface. The value $\Delta G_{a d s}^{o}$ for tested inhibitor is $-35.73 \mathrm{~kJ} \mathrm{~mol}^{-1}$. This proves that the mechanism of adsorption of the EMTP on the MS surface was physisorption and chemisorption adsorbed mechanism. The anticorrosion mechanism of mild steel in a corrosive environment by the EMTP molecules can be defined based on the adsorption on the mild steel surface. The EMTP molecules act by adsorption on the mild steel surface that prevents the active positions by displacing water molecules and creating a layer to block the corrosion process [30]. Figure 8 represent the suggested inhibition mechanism of EMTP on the MS surface in $1 \mathrm{M} \mathrm{HCl}$ solution.

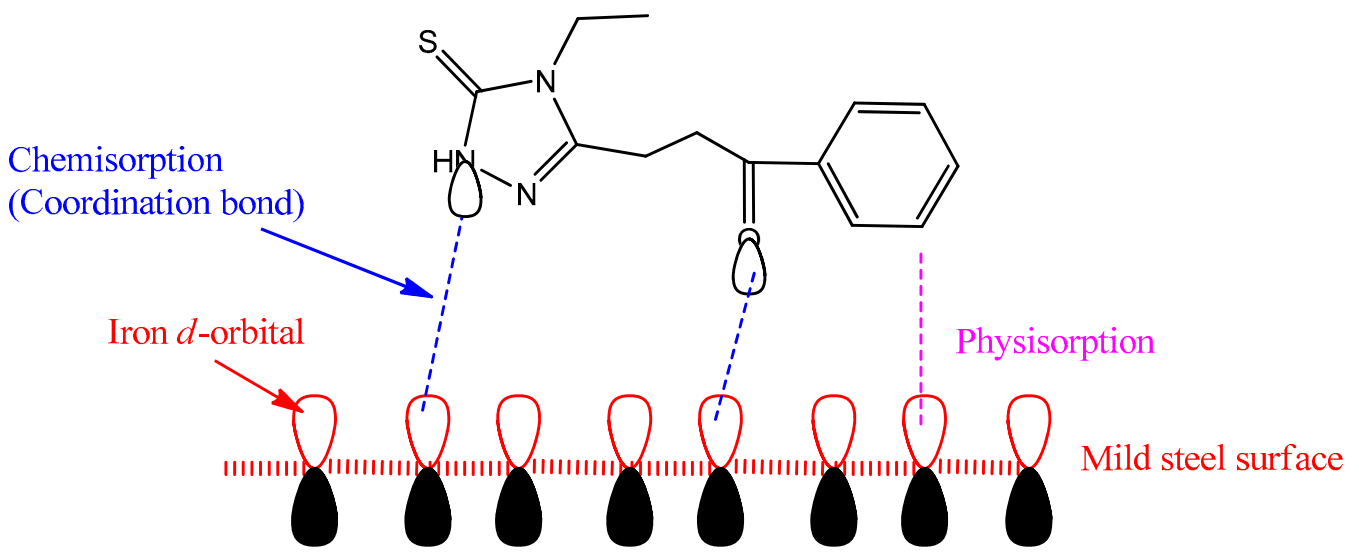

Figure 8. The suggested inhibition mechanism of EMTP on the MS surface in $1 \mathrm{M} \mathrm{HCl}$ solution.

\section{Conclusions}

The anticorrosion efficiency of EMTP has been examined by weight loss techniques and quantum chemical computation. The parameters influencing the anticorrosion such as the structure of the inhibitor molecules, the concentration of the tested inhibitor, immersion time, and temperature are studied. Here are the main conclusions:

1. EMTP is a promising corrosion inhibitor for mild steel in $1.0 \mathrm{M}$ hydrochloric acid solution with the highest protection efficacy of $97 \%$ at $303 \mathrm{~K}$.

2. The weight loss findings implied that EMTP protects the metal surface corrosion through the creation of a protective layer at the surface mild steel-corrosive solution interface.

3. The inhibitive efficacy increases with the increase of inhibitor concentration and decreases with increased temperature.

4. The adsorption of tested inhibitor molecules in $1.0 \mathrm{M} \mathrm{HCl}$ follows the Langmuir adsorption isotherm model.

5. The corrosion protection performance of tested inhibitor molecules has been further evaluated through theoretical computations. In conclusion, weight loss and computational calculations result are in good agreement. 
6. From free energy results, it can be concluded that the adsorption of tested inhibitor molecules on mild steel surfaces follow both physisorption and chemisorption mechanisms.

Author Contributions: Conceptualization, L.M.S.; methodology, A.A.A. and W.N.R.W.I. software, L.M.S.; validation, I.A.A.A. and M.S.T.; investigation, M.H.A. (Makarim H. Abdulkareem) and M.H.A. (Mohammed H. Alkaabi); resources, W.N.R.W.I. and M.S.T.; data curation, A.A.A.; writingoriginal draft preparation, I.A.A.A. and A.A.A.; writing-review and editing, I.A.A. and M.M.H.; visualization, M.S.T.; supervision, A.A.A. All authors have read and agreed to the published version of the manuscript.

Funding: This research received no external funding.

Institutional Review Board Statement: Not Applicable.

Informed Consent Statement: Not Applicable.

Data Availability Statement: The data of this study are available from the corresponding author (A.A.A.), upon reasonable request.

Acknowledgments: The authors thank Universiti Kebangsaan Malaysia (Malaysia) and University of Technology (Iraq) for supporting this work.

Conflicts of Interest: The authors declare no conflict of interest.

\section{References}

1. Jacob, K.S.; Parameswaran, G. Corrosion inhibition of mild steel in hydrochloric acid solution by Schiff base furoin thiosemicarbazone. Corros. Sci. 2010, 52, 224-228. [CrossRef]

2. Haldhar, R.; Prasad, D.; Saharan, H. Performance of Pfaffia paniculata extract towards corrosion mitigation of low-carbon steel in an acidic environment. Int. J. Ind. Chem. 2020, 11, 72. [CrossRef]

3. Haldhar, R.; Prasad, D.; Bhardwaj, N. Surface adsorption and corrosion resistance performance of Acacia concinna pod extract: An efficient inhibitor for mild steel in acidic environment. Arab. J. Sci. Eng. 2020, 45, 131-141. [CrossRef]

4. Haldhar, R.; Prasad, D. Corrosion resistance and surface protective performance of waste material of Eucalyptus globulus for low carbon steel. J. Bio-Tribo-Corros. 2020, 6, 48. [CrossRef]

5. Haldhar, R.; Prasad, D.; Bhardwaj, N. Experimental and theoretical evaluation of acacia catechu extract as a natural, economical and effective corrosion inhibitor for mild steel in an acidic environment. J. Bio-Tribo-Corros. 2020, 6, 76. [CrossRef]

6. Haldhar, R.; Prasad, D.; Kamboj, D.; Kaya, S.; Dagdag, O.; Guo, L. Corrosion inhibition, surface adsorption and computational studies of Momordica charantia extract: A sustainable and green approach. SN Appl. Sci. 2021, 3, 25. [CrossRef]

7. Zheludkevich, M.L.; Yasakau, K.A.; Poznyak, S.K.; Ferreira, M.G. Triazole and thiazole derivatives as corrosion inhibitors for AA2024 aluminium alloy. Corros. Sci. 2005, 47, 3368-3383. [CrossRef]

8. Zhang, S.; Tao, Z.; Liao, S.; Wu, F. Substitutional adsorption isotherms and corrosion inhibitive properties of some oxadiazoltriazole derivative in acidic solution. Corros. Sci. 2010, 52, 3126-3132. [CrossRef]

9. Wang, H.L.; Liu, R.B.; Xin, J. Inhibiting effects of some mercapto-triazole derivatives on the corrosion of mild steel in $1.0 \mathrm{M} \mathrm{HCl}$ medium. Corros. Sci. 2004, 46, 2455-2466. [CrossRef]

10. Bentiss, F.; Lagrenee, M.; Traisnel, M.; Hornez, J.C. The corrosion inhibition of mild steel in acidic media by a new triazole derivative. Corros. Sci. 1999, 41, 789-803. [CrossRef]

11. Sherif, E.M.; Park, S.M. Effects of 1, 4-naphthoquinone on aluminum corrosion in $0.50 \mathrm{M}$ sodium chloride solutions. Electrochim. Acta 2006, 51, 1313-1321. [CrossRef]

12. Mu, G.N.P.; Zhao, T.; Liu, M.; Gu, T. Effect of metallic cations on corrosion inhibition of an anionic surfactant for mild steel. Corrosion 1996, 52, 853-856. [CrossRef]

13. Al-Baghdadi, S.B.; Noori, F.T.; Ahmed, W.K.; Al-Amiery, A.A. Thiadiazole as a potential corrosion inhibitor for mild steel in $1 \mathrm{M}$ HCl. J. Adv. Electrochem. 2016, 18, 67-69.

14. Jawad, Q.A.; Zinad, D.S.; Dawood Salim, R.; Al-Amiery, A.A.; Sumer Gaaz, T.; Takriff, M.S.; Kadhum, A.A.H. Synthesis, characterization, and corrosion inhibition potential of novel thiosemicarbazone on mild steel in sulfuric acid environment. Coatings 2019, 9, 729. [CrossRef]

15. Al-Amiery, A.A.; Ahmed, M.H.; Abdullah, T.A.; Gaaz, T.S.; Kadhum, A.A. Electrochemical studies of novel corrosion inhibitor for mild steel in $1 \mathrm{M}$ hydrochloric acid. Results Phys. 2018, 9, 978-981. [CrossRef]

16. Hussein, H.T.; Kadhim, A.; Al-Amiery, A.A.; Kadhum, A.A.; Mohamad, A.B. Enhancement of the wear resistance and microhardness of aluminum alloy by Nd: YaG laser treatment. Sci. World J. 2014, 2014, 842062. [CrossRef]

17. Issa, A.Y.; Rida, K.S.; Salam, A.Q.; Al-Amiery, A.A. Acetamidocoumarin as a based eco-friendly corrosion inhibitor. Int. J. ChemTech Res. 2016, 9, 39-47. 
18. Salim, R.D.; Jawad, Q.A.; Ridah, K.S.; Shaker, L.M.; Al-Amiery, A.A.; Kadhum, A.A.; Takriff, M.S. Corrosion inhibition of thiadiazole derivative for mild steel in hydrochloric acid solution. Int. J. Corros. Scale Inhib. 2020, 9, 550-561.

19. Al-Amiery, A.A.; Shaker, L.M.; Kadhum, A.A.; Takriff, M.S. Corrosion Inhibition of Mild Steel in Strong Acid Environment by 4-((5, 5-dimethyl-3-oxocyclohex-1-en-1-yl) amino) benzenesulfonamide. Tribol. Ind. 2020, 42, 89-101. [CrossRef]

20. Musa, A.Y.; Mohamad, A.B.; Al-Amiery, A.A.; Tien, L.T. Galvanic corrosion of aluminum alloy (Al2024) and copper in 1.0 M hydrochloric acid solution. Korean J. Chem. Eng. 2012, 29, 818-822. [CrossRef]

21. Kadhim, A.; Al-Amiery, A.A.; Alazawi, R.; Al-Ghezi, M.K.; Abass, R.H. Corrosion inhibitors. A review. Int. J. Corros. Scale Inhib. 2021, 10, 54-67.

22. Abu-Hashem, A.A. Synthesis and antimicrobial activity of new 1, 2, 4-triazole, 1, 3, 4-oxadiazole, 1, 3, 4-thiadiazole, thiopyrane, thiazolidinone, and azepine derivatives. J. Heterocycl. Chem. 2021, 58, 74-92. [CrossRef]

23. ASTM G-31-72. Standard Recommended Practice for the Laboratory Immersion Corrosion Testing of Metals; ASTM: Philaldelphia, PA, USA, 1990; p. 401.

24. Al-Amiery, A.A.; Shaker, L.M. Corrosion inhibition of mild steel using novel pyridine derivative in 1 M hydrochloric acid. Koroze A Ochr. Mater. 2020, 64, 59-64. [CrossRef]

25. Alamiery, A.; Mahmoudi, E.; Allami, T. Corrosion inhibition of low-carbon steel in hydrochloric acid envi-ronment using a Schiff base derived from pyrrole: Gravimetric and computational studies. Int. J. Corros. Scale Inhib 2021, 10, 749-765.

26. Alamiery, A.A. Anticorrosion effect of thiosemicarbazide derivative on mild steel in $1 \mathrm{M}$ hydrochloric acid and $0.5 \mathrm{M}$ sulfuric Acid: Gravimetrical and theoretical studies. Mater. Sci. Energy Technol. 2021, 4, 263-273. [CrossRef]

27. Koopmans, T. Ordering of wave functions and eigenenergies to the individual electrons of an atom. Physica 1933, 1, 104-113. [CrossRef]

28. Salim, R.D.; Betti, N.; Hanoon, M.; Al-Amiery, A.A. 2-(2, 4-Dimethoxybenzylidene)-N-Phenylhydrazinecarbothioamide as an Efficient Corrosion Inhibitor for Mild Steel in Acidic Environment. Prog. Color Colorants Coat. 2022, 15, 45-52.

29. Shaker, L.M.; Al-Adili, A.; Al-Amiery, A.A.; Takriff, M.S. The inhibition of mild steel corrosion in $0.5 \mathrm{M} \mathrm{H}_{2} \mathrm{SO}_{4}$ solution by N-phenethylhydrazinecarbothioamide (N-PHC). In Journal of Physics: Conference Series; IOP Publishing: Bristol, UK, 2021; Volume 1795, p. 012009.

30. Alamiery, A.; Mohamad, A.; Kadhum, A.; Takriff, M. The synergistic role of azomethine group and triazole ring at improving the anti-corrosive performance of 2-amino-4-phenylthiazole. South Afr. J. Chem. Eng. 2021, 38, 41-53. [CrossRef]

31. Al-Amiery, A.; Shaker, L.M.; Kadhum, A.A.; Takriff, M.S. Synthesis, characterization and gravimetric studies of novel triazolebased compound. Int. J. Low-Carbon Technol. 2020, 15, 164-170. [CrossRef]

32. Al-Taweel, S.S.; Al-Janabi, K.W.; Luaibi, H.M.; Al-Amiery, A.A.; Gaaz, T.S. Evaluation and characterization of the symbiotic effect of benzylidene derivative with titanium dioxide nanoparticles on the inhibition of the chemical corrosion of mild steel. Int. J. Corros. Scale Inhib. 2019, 8, 1149-1169.

33. Nahlé, A.; Salim, R.; El Hajjaji, F.; Aouad, M.R.; Messali, M.; Ech-Chihbi, E.; Hammouti, B.; Taleb, M. Novel triazole derivatives as ecological corrosion inhibitors for mild steel in $1.0 \mathrm{M} \mathrm{HCl}$ : Experimental \& theoretical approach. RSC Adv. 2021, 11, 4147-4162.

34. Espinoza-Vázquez, A.; Rodríguez-Gómez, F.J; Martínez-Cruz, I.K.; Ángeles-Beltrán, D.; Negrón-Silva, G.E.; Palomar-Pardavé, M.; Romero, L.L.; Pérez-Martínez, D.; Navarrete-López, A.M. Adsorption and corrosion inhibition behaviour of new theophyllinetriazole-based derivatives for steel in acidic medium. R. Soc. Open Sci. 2019, 6, 181738. [CrossRef]

35. Merimi, I.; Benkaddour, R.; Lgaz, H.; Rezki, N.; Messali, M.; Jeffali, F.; Oudda, H.; Hammouti, B. Insights into corrosion inhibition behavior of a triazole derivative for mild steel in hydrochloric acid solution. Mater. Today Proc. 2019, 13, 1008-1022. [CrossRef]

36. Wang, L.; Zhu, M.J.; Yang, F.C.; Gao, C.W. Study of a triazole derivative as corrosion inhibitor for mild steel in phosphoric acid solution. Int. J. Corros. 2012, 2012, 573964. [CrossRef]

37. Bentiss, F.; Bouanis, M.; Mernari, B.; Traisnel, M.; Vezin, H.; Lagrenee, M. Understanding the adsorption of 4H-1, 2, 4-triazole derivatives on mild steel surface in molar hydrochloric acid. Appl. Surf. Sci. 2007, 253, 3696-3704. [CrossRef]

38. El Mehdi, B.; Mernari, B.; Traisnel, M.; Bentiss, F.; Lagrenee, M. Synthesis and comparative study of the inhibitive effect of some new triazole derivatives towards corrosion of mild steel in hydrochloric acid solution. Mater. Chem. Phys. 2003, 77, 489-496. [CrossRef]

39. Hassan, H.H.; Abdelghani, E.; Amin, M.A. Inhibition of mild steel corrosion in hydrochloric acid solution by triazole derivatives: Part I. Polariz. EIS Studies Electrochim. Acta 2007, 52, 6359-6366. [CrossRef]

40. Ramesh, S.; Rajeswari, S. Corrosion inhibition of mild steel in neutral aqueous solution by new triazole derivatives. Electrochim. Acta 2004, 49, 811-820. [CrossRef]

41. Qiu, L.G.; Xie, A.J.; Shen, Y.H. A novel triazole-based cationic gemini surfactant: Synthesis and effect on corrosion inhibition of carbon steel in hydrochloric acid. Mater. Chem. Phys. 2005, 91, 269-273. [CrossRef]

42. Mert, B.D.; Mert, M.E.; Kardaş, G.; Yazıc1, B. Experimental and theoretical investigation of 3-amino-1, 2, 4-triazole-5-thiol as a corrosion inhibitor for carbon steel in $\mathrm{HCl}$ medium. Corros. Sci. 2011, 53, 4265-4272. [CrossRef]

43. Salman, T.A.; Al-Amiery, A.A.; Shaker, L.M.; Kadhum, A.A.; Takriff, M.S. A study on the inhibition of mild steel corrosion in hydrochloric acid environment by 4-methyl-2-(pyridin-3-yl) thiazole-5-carbohydrazide. Int. J. Corros. Scale Inhib. 2019, 8, 1035-1059.

44. Habeeb, H.J.; Luaibi, H.M.; Abdullah, T.A.; Dakhil, R.M.; Kadhum, A.A.; Al-Amiery, A.A. Case study on thermal impact of novel corrosion inhibitor on mild steel. Case Stud. Therm. Eng. 2018, 12, 64-68. [CrossRef] 
45. Quraishi, M.A.; Sharma, H.K. 4-Amino-3-butyl-5-mercapto-1, 2, 4-triazole: A new corrosion inhibitor for mild steel in sulphuric acid. Mater. Chem. Phys. 2003, 78, 18-21. [CrossRef]

46. Poornima, T.; Nayak, J.; Shetty, A.N. Corrosion inhibition of the annealed $18 \mathrm{Ni} 250$ grade maraging steel in $0.67 \mathrm{~m}$ phosphoric acid by 3, 4-dimethoxybenzaldehydethiosemicarbazone. Chem. Sci. J. 2012, 69, 1-13.

47. Abdallah, M.; Helal, E.A.; Fouda, A.S. Aminopyrimidine derivatives as inhibitors for corrosion of 1018 carbon steel in nitric acid solution. Corros. Sci. 2006, 48, 1639-1654. [CrossRef]

48. Salman, T.A.; Jawad, Q.A.; Hussain, M.A.; Al-Amiery, A.A.; Mohamed, L.; Kadhum, A.A.; Takriff, M.S. Novel ecofriendly corrosion inhibition of mild steel in strong acid environment: Adsorption studies and thermal effects. Int. J. Corros. Scale Inhib. 2019, 8, 1123-1137.

49. Alamiery, A.A. Effect of Temperature on the Corrosion Inhibition of 4-ethyl-1-(4-oxo-4-phenylbutanoyl). Lett. Appl. NanoBioScience 2022, 11, 3502-3508.

50. Alamiery, A. Corrosion inhibition effect of 2-N-phenylamino-5-(3-phenyl-3-oxo-1-propyl)-1, 3, 4-oxadiazole on mild steel in 1 M hydrochloric acid medium: Insight from gravimetric and DFT investigations. Mater. Sci. Energy Technol. 2021, 4, 398-406. [CrossRef]

51. Alamiery, A.A.; Wan Isahak, W.N.; Takriff, M.S. Inhibition of Mild Steel Corrosion by 4-benzyl-1-(4-oxo-4-phenylbutanoyl) thiosemicarbazide: Gravimetrical, Adsorption and Theoretical Studies. Lubricants 2021, 9, 93. [CrossRef]

52. Jamil, D.M.; Al-Okbi, A.K.; Hanon, M.M.; Rida, K.S.; Alkaim, A.F.; Al-Amiery, A.A.; Kadhim, A.; Kadhum, A.A. Carbethoxythiazole corrosion inhibitor: As an experimentally model and DFT theory. J. Eng. Appl. Sci. 2018, 13, 3952-3959.

53. Musa, A.Y.; Ahmoda, W.; Al-Amiery, A.A.; Kadhum, A.A.; Mohamad, A.B. Quantum chemical calculation for the inhibitory effect of compounds. J. Struct. Chem. 2013, 54, 301-308. [CrossRef]

54. Al-Baghdadi, S.; Gaaz, T.S.; Al-Adili, A.; Al-Amiery, A.A.; Takriff, M.S. Experimental studies on corrosion inhibition performance of acetylthiophene thiosemicarbazone for mild steel in $\mathrm{HCl}$ complemented with DFT investigation. Int. J. Low-Carbon Technol. 2021, 16, 181-188. [CrossRef]

55. Al-Amiery, A.; Salman, T.A.; Alazawi, K.F.; Shaker, L.M.; Kadhum, A.A.; Takriff, M.S. Quantum chemical elucidation on corrosion inhibition efficiency of Schiff base: DFT investigations supported by weight loss and SEM techniques. Int. J. Low-Carbon Technol. 2020, 15, 202-209. [CrossRef]

56. Salman, T.A.; Al-Azawi, K.F.; Mohammed, I.M.; Al-Baghdadi, S.B.; Al-Amiery, A.A.; Gaaz, T.S.; Kadhum, A.A. Experimental studies on inhibition of mild steel corrosion by novel synthesized inhibitor complemented with quantum chemical calculations. Results Phys. 2018, 10, 291-296. [CrossRef]

57. Zinad, D.S.; Jawad, Q.A.; Hussain, M.A.; Mahal, A.; Mohamed, L.; Al-Amiery, A.A. Adsorption, temperature and corrosion inhibition studies of a coumarin derivatives corrosion inhibitor for mild steel in acidic medium: Gravimetric and theoretical investigations. Int. J. Corros. Scale Inhib. 2020, 9, 134-151.

58. Zinad, D.S.; Hanoon, M.; Salim, R.D.; Ibrahim, S.I.; Al-Amiery, A.A.; Takriff, M.S.; Kadhum, A.A. A new synthesized coumarinderived Schiff base as a corrosion inhibitor of mild steel surface in $\mathrm{HCl}$ medium: Gravimetric and DFT studies. Int. J. Corros. Scale Inhib. 2020, 9, 228-243.

59. Yamin, J.A.; Sheet, E.A.; Al-Amiery, A. Statistical analysis and optimization of the corrosion inhibition efficiency of a locally made corrosion inhibitor under different operating variables using RSM. Int. J. Corros. Scale Inhib. 2020, 9, 502-518.

60. Salman, T.A.; Zinad, D.S.; Jaber, S.H.; Al-Ghezi, M.; Mahal, A.; Takriff, M.S.; Al-Amiery, A.A. Effect of 1, 3, 4-thiadiazole scaffold on the corrosion inhibition of mild steel in acidic medium: An experimental and computational study. J. Bio-Tribo-Corros. 2019, 5, 11. [CrossRef]

61. Al-Baghdadi, S.B.; Al-Amiery, A.A.; Kadhum, A.A.; Takriff, M.S. Computational Calculations, Gravimetrical, and Surface Morphological Investigations of Corrosion Inhibition Effect of Triazole Derivative on Mild Steel in HCl. J. Comput. Theor. Nanosci. 2020, 17, 2897-2904. [CrossRef]

62. Hanoon, M.M.; Gbashi, Z.A.; Al-Amiery, A.A.; Kadhim, A.; Kadhum, A.A.; Takriff, M.S. Study of Corrosion Behavior of N'-acetyl4-pyrrol-1-ylbenzohydrazide for Low-Carbon Steel in the Acid Environment: Experimental, Adsorption Mechanism, Surface Investigation, and DFT Studies. Prog. Color Colorants Coat. 2022, 15, 133-141.

63. Hanoon, M.M.; Resen, A.M.; Al-Amiery, A.A.; Kadhum, A.A.; Takriff, M.S. Theoretical and Experimental Studies on the Corrosion Inhibition Potentials of 2-((6-Methyl-2-Ketoquinolin-3-yl) Methylene) Hydrazinecarbothioamide for Mild Steel in $1 \mathrm{M}$ HCl. Prog. Color Colorants Coat. 2022, 15, 11-23. 